\title{
Gestão em Fisioterapia Hospitalar: foco em resultados e excelência operacional
}

Vanessa Chaves Barreto Ferreira de Lima

Veronica Altheman

HOSPITAL SAMARITANO DE SÃO PAULO

\section{INTRODUÇÃO}

As instituições de saúde enfrentam desafios diários que impõem a necessidade de soluções rápidas e inovadoras para garantir a qualidade na assistência, ao mesmo passo que são impulsionadas a obter melhor desempenho operacional e financeiro.

\section{OBJETIVO}

Reestruturar o modelo de gestão e processos de trabalho do serviço de fisioterapia.

\section{MÉTODO}

Com olhar voltado para eficiência, o Serviço de Fisioterapia reestruturou seus processos utilizando como metodologia ferramentas de qualidade para analisar, mensurar, reorganizar e definir um novo conceito de gestão para o setor. As principais ferramentas utilizadas foram: Brainstorming, Diagrama de Ishikawa, 5W2H e PDCA.

A primeira etapa do projeto focou quatro principais pontos de atenção para início do processo de reestruturação (figura 1).

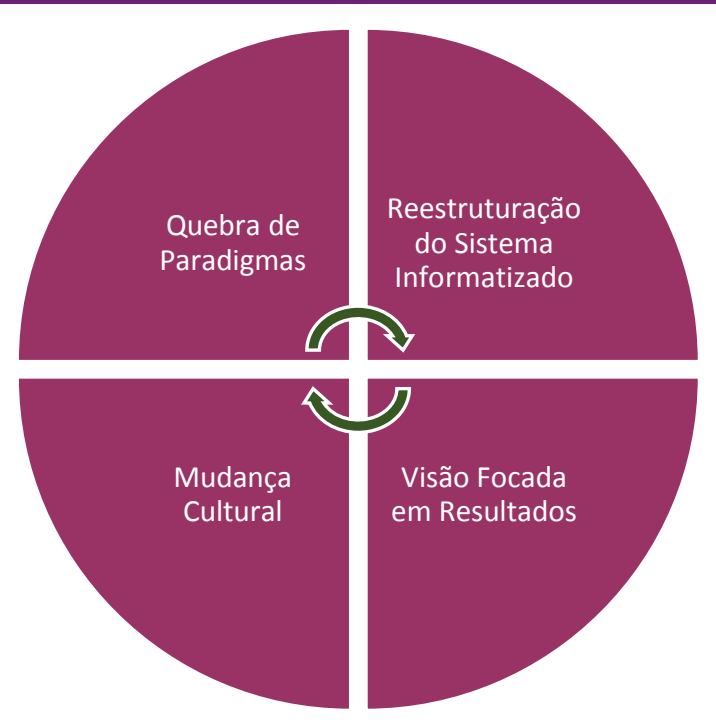

Figura 1: Principais pontos de atenção

\section{RESULTADO}

Ao final do ano de 2015 os primeiros frutos foram perceptíveis, com aumento de receita em 34\% e 18\% em produção, contribuindo para um resultado direto $70 \%$ maior (gráfico 1). É importante destacar que, o comprometimento da receita com custo fixo reduziu de 58\% para $50 \%$ após implantação do projeto, (gráfico 2).

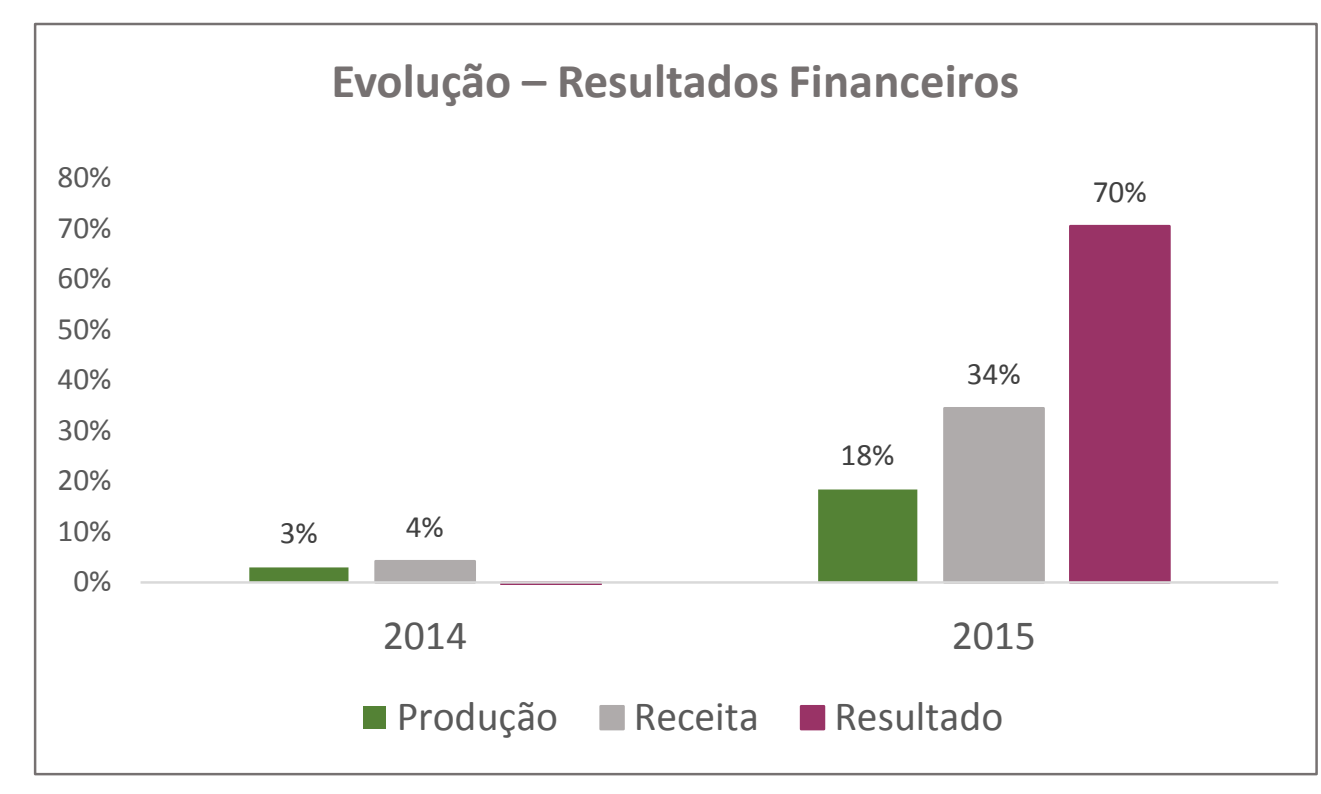

Gráfico 1: Evolução dos Resultados Financeiros

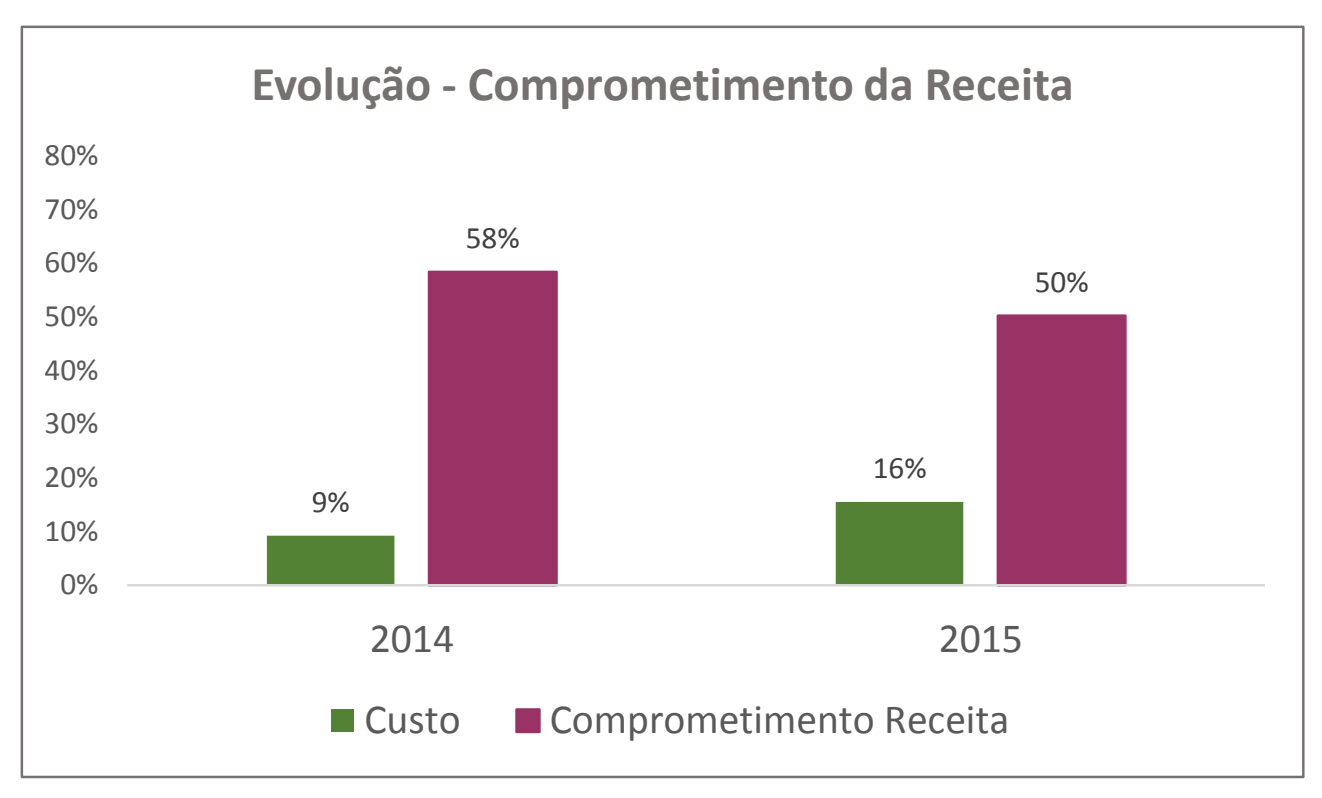

Gráfico 2: Evolução do Comprometimento da Receita

Além dos resultados financeiros, é imprescindível mencionar a mudança comportamental da equipe, a qual passou a atuar com postura accountability, bem como, olhar analítico e associado à utilização racional de recursos visando o melhor custo beneficio.

\section{Bibliografias}

Westby MD, Klemm A, Li LA, Jones CA. Emerging role of quality indicators in physical therapist practice and health service delivery. Phys Ther 2015 ; 95. Neto GV, Malik AM. Gestão em saúde. São Paulo: Editora: Guanabara Koogan, 2011.

Werkema MCC. As ferramentas da qualidade no gerenciamento de processos. Belo Horizonte: UFMG; Fundação Christiano Ottoni, 1995. 